\title{
The Pattern of Facial Injury among Foreign Travelers in Bali: A Retrospective Study
}

\author{
Nyoman P. Riasa ${ }^{1}$, Ardhy Parama ${ }^{2}$, Putu Indah Budiapsari ${ }^{3 *}$, Desak Putu Oki Lestari ${ }^{4}$ \\ ${ }^{1}$ Department of Surgery, Plastic Surgery Division, Faculty of Medicine, Universitas Udayana, Rumah Sakit Umum Pusat Sanglah, \\ Denpasar, Indonesia; ${ }^{2}$ Department of Emergency, Beth Israel Medical Center Hospital Kuta, Bali, Indonesia; ${ }^{3}$ Department \\ of Parasitology, Travel's Health Unit, Faculty of Medicine, Universitas Warmadewa, Denpasar, Indonesia; ${ }^{4}$ Department of \\ Pathology, Universitas Warmadewa, Denpasar, Indonesia
}

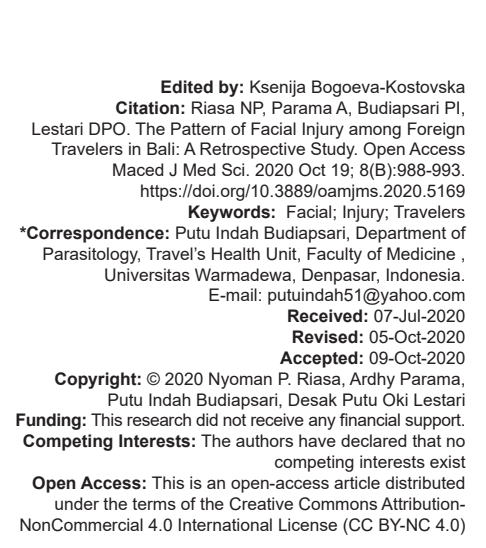

\begin{abstract}
BACKGROUND: Injury, especially road traffic accident caused injury, was the most cause of death in international traveler worldwide. Estimated more than 1 million people deaths and become disability after injury. Facial fracture was the most common injury in plastic surgery division among international traveler.

AIM: This study is aimed to describe the pattern of facial fracture among foreign travelers in Bali to provide prompt prevention and treatment.

METHODS: The retrospective study was did using the medical record, imaging analysis including computed tomographies and conventional radiographs of 126 cases of facial fracture from the period of January 2009 to September 2012. The patterns of facial fractures were divided into four main categories of craniofacial, maxillofacial, nasal, and mandibulofacial.

RESULTS: The result showed that fractures involving nasal region were the most common $(n=65,51.6 \%)$ followed by midface region $(n=58,46.0 \%)$, craniofacial $(n=50,39.7 \%)$, and mandibulofacial $(n=20,15.9 \%)$, respectively.

CONCLUSION: It can be concluded, nasal fracture and midfacial fracture were the most common type of facial fracture with the major cause of motor vehicle accidents.
\end{abstract}

\section{Introduction}

Facial injury remains the most common trauma that requires particular attention due to its specific anatomical region and its major impact on functional and esthetic aspects [1], [2]. These injuries can be presented in isolation or combination with other injuries [3], [4]. Their cause and incidence vary from one country to another [5], [6], depending on the social, cultural, and environmental factors [7] and lead to the difference in the pattern of facial fracture. For instance, the pattern of facial fractures in the area where the violence as the major cause might be different from those where the sport or traffic accident plays their major cause [1], [8], [9].

In Bali, as one of the world tourism destinations, there is limited study describing facial injury, particularly in foreigners. Our center is located in one of the most common visited areas in Bali. Hence, performing research involving foreigners might be possible. This study was, therefore, essential to explain the general epidemiologic condition of facial injury among foreigners traveling in Bali regarding their patterns, common causes, and principal demography to provide a clear understanding of the pattern of facial injury in a tourism destination. Besides, as a guide to the design of programs geared toward prevention and management.

\section{Methods}

The retrospective descriptive study recruited 129 cases with facial fracture in our center, obtained from January 2009 to September 2012. All were studied based on the review of the medical report, administrative data, as well as the analysis of imaging results including head and maxillofacial computed tomography and conventional radiographs. Among them, three cases were excluded due to their incomplete data.

Principal demographic conditions of 126 cases were then analyzed by the sex, age, time of referrals, causes or mechanism of injury, as well as the type of management. The concomitant injury is also the subject of review. The prevalence of age and time of referral was distributed into interval categories. 
Based on direct analysis of imaging modalities in comparison to clinical diagnosis as well as radiologist official reading, we categorized facial fracture into four major regions (Figure 1). The first is a region of craniofacial which comprises fractures affecting the orbital floor up to frontal sinuses. The maxillofacial or midfacial region encompasses a middle third area of the face between orbital floor down to a line projecting horizontally across the alveolar process of the maxilla. The mandibulofacial region comprises fractures affecting mandibular and temporomandibular joints. We separated a nasal as the fourth region since its incidence is common and varies in the configuration. The number of specific fractures related to the region was then counted.

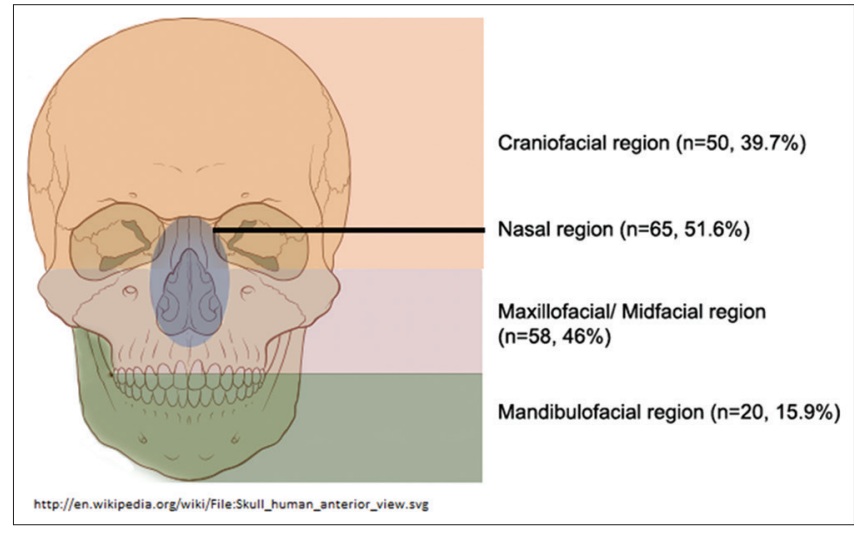

Figure 1: Fractures distribution according to the four facial regions

In defining pattern of zygomatic fracture, we rely on dual axial buttress in establishing the optimum fixation of the zygomatic fracture, that is, horizontal buttress which is supported by inferior orbital rim running down to anterior maxillary sinus wall, and zygomatic arch, and vertical buttress being supported by the lateral orbital rim and lateral wall of the maxillary sinus. Hence, the term of four-legged type fracture describes the fracture involving all four supports system, while tripod type affects three of them. Zygomaticomaxillary complex fracture is a fracture involving a zygomaticomaxillary junction where the zygomatic arch and lateral orbital rim remain intact.

\section{Results}

A total of 126 showed most cases of $89(70.6 \%)$ were male, the age ranged $16-30$ years old $(n=66$, $52.4 \%$ ). Motor vehicle accident (MVA) contributed the majority of the cause of injury, about 48 cases were recorded $(38.1 \%)$ and most of them presented with head injury ( $\mathrm{n}=79,62.7 \%)$ as the common accompanying injury and received the initial treatment within $12 \mathrm{~h}$ following the injury ( $n=98,77.8 \%$ ).

Basic demographic data showed that $70.6 \%$ $(89 / 126)$ of cases were male, about 2.4:1 for the overall ratio of male to female. The highest frequency of facial fractures was found in the age group of 16-30 years old which comprises $52.4 \%$ of all cases $(n=66)$. The cases were distributed into age intervals, as shown in Diagram 1. The frequency of facial fractures declines by the advance of the age and tends to be low at an earlier age.

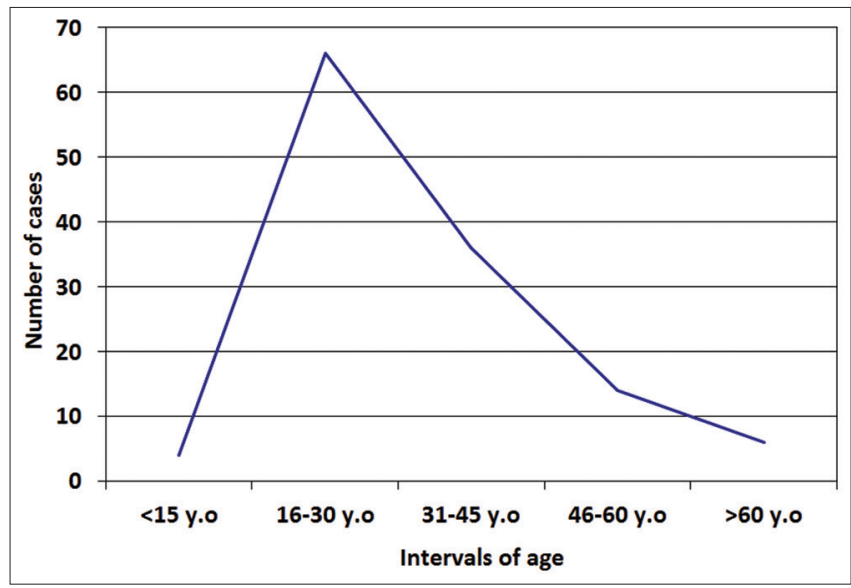

Diagram 1: Number of cases according to age distribution

The etiologies of facial fractures in our center varied which the major causative factor was MVA comprising $38.1 \%(n=48)$ of all cases and falls rank the second most common cause of $20.6 \%(n=26)$, followed by assault ( $n=21,16.7 \%$ ), sport-related injury $(n=21,16.7 \%)$, and traffic accident $(n=5,3.9 \%)$, respectively. There were 5 cases $(3.9 \%)$ found with unidentified cause due to incomplete history reported in the medical report. All cases were referred to our center with the variation of time interval following the injury. Most of them, about $77.8 \%(n=98)$, received initial medical management within $12 \mathrm{~h}$ following the injury. There are 8 cases reported $(6.3 \%)$ receiving treatment within $12-24$ h, 7 cases (5.6\%) within 24-36 h, and 2 cases $(1.6 \%)$ were referred within interval $36-48 \mathrm{~h}$. The longer the interval the lesser amount of cases referred. However, 11 cases $(8.7 \%)$ were identified as being referred to for more than $48 \mathrm{~h}$. The longest interval reported was 15 days.

About $46.8 \%(n=59)$ of cases underwent surgery in our center. The remaining were either treated conservatively ( $n=36,28.6 \%)$ or in the condition where surgery was indicated but not performed due to nonmedical reasons $(n=22,17.5 \%)$. In other cases, surgery was delayed due to more threatening accompanying injury $(n=9,7.1 \%)$.

Head injury constitutes the major proportion of accompanying injury ( $n=79,62.7 \%)$ (Table 1 ), presented in different level of consciousness. Maxillofacial softtissue injury places the second rank $(n=71,56.3 \%)$. From all cases reviewed, none of them presented with an abdominopelvic injury.

According to the classification of four different facial regions, that is, craniofacial $(C)$, maxillofacial $(\mathrm{M})$, nasal $(\mathrm{N})$, and mandibulofacial (MI), we found the 
Table 1: Accompanying injury (numbers in bold indicates in comparison to total cases)

\begin{tabular}{lll}
\hline Accompanying injuries & No. of case & $\%$ \\
\hline Head injury $(\mathrm{n}=79)$ & 79 & 62.7 \\
Mild (GCS 14-15) & 65 & 82.3 \\
Moderate (GCS 8-13) & 9 & 11.4 \\
Severe (GCS <8) & 4 & 5.1 \\
Level undetermined & 1 & 1.3 \\
Cervical injury $(\mathrm{n}=6)$ & 6 & 4.8 \\
Cervical soft-tissue injury & 3 & 50 \\
Cervical fracture & 3 & 50 \\
Maxillofacial soft-tissue injury ( $\mathrm{n}=71)$ & 71 & 56.3 \\
Open wound & 64 & 90.1 \\
Skin avulsion & 1 & 1.4 \\
Cranial nerve injury & 6 & 8.5 \\
Injury on extremities & 12 & 9.5 \\
Other (non-facial) soft-tissue injury & 13 & 10.3 \\
Thoracic injury & 8 & 6.3 \\
Abdominopelvic injury & 0 & 0 \\
Spinal injury (fracture) & 1 & 0.8 \\
Cranial bone fracture & 4 & 3.2 \\
Dental injury & 6 & 4.8 \\
Ocular injury & 3 & 2.4 \\
\hline *Bold numbers indicate in comparison to whole cases & &
\end{tabular}

fractures on nasal $(\mathrm{N})$ region as the highest prevalence fractures contributing $51.6 \%(n=65)$ of all cases, followed by the maxillofacial or midfacial region of $46.0 \%(n=58)$, craniofacial region $(39.7 \%, n=50)$, and mandibulofacial $(15.9 \%, \mathrm{n}=20)$, respectively (Figure 1). All were presented either in an isolated or in combination with other regions (Table 2).

Table 2: Distribution of facial fractures based on the classified regions

\begin{tabular}{lll}
\hline Region & No. of cases & $\%$ \\
\hline Isolated region & & \\
Craniofacial (C) & 11 & 8.7 \\
Maxillofacial (M) & 12 & 9.5 \\
Nasal (N) & 41 & 32.5 \\
Mandibulofacial (MI) & 12 & 9.5 \\
Combined regions & & \\
C-N & 3 & 2.4 \\
C-M & 22 & 17.5 \\
M-N & 7 & 5.6 \\
C-M-Ml & 2 & 1.6 \\
M-Ml & 2 & 1.6 \\
C-M-N & 10 & 7.9 \\
Panfacial & 2 & 1.6 \\
C-Ml & 0 & 0 \\
M-N-Ml & 1 & 0.8 \\
N-Ml & 1 & 0.8 \\
\hline
\end{tabular}

Among 50 cases of the fractures affecting the craniofacial region, the orbital fractures were the most common fracture $(n=46,92 \%)$, while fracture of zygoma dominated the number of fractures involving midfacial region $(n=30,51.7 \%)$. No Le Fort II or III was found in our study. Fractures of nasal bone with no associated septal deviation encompassed the majority of fracture in the nasal region reported 29 cases (44.6\%). About $60 \%$ of fractures in the mandibulofacial region were multiple fractures where ramus of the mandible was the common site involved $(n=13.65 \%)$ (Table 3$)$.

\section{Discussion}

Facial fractures leave the greatest challenge in their management due to their complex and overlapping anatomical structures as well as its impact on function and esthetic appearances [1], [2]. It is of considerable concern when their pattern is greatly variable in different places in the world [5], [6]. Differences in mechanism and cause of injury result in different patterns of facial fractures [1], [3], [4], [5], [6], [9], [10], [11], [12], [13], [14], [15], [16], [17], [18]. Compared to a similar study performed in other different countries, there was no significant difference regarding principal demographic profiles found in our study. Male sustained more injuries. This might be contributed by the fact that male is more projected to personal violence, drug use, accident, etc., due to their involvement in productive population. However, its ratio compared to females found 2.4:1 in our study, differs significantly to those found in some previously published review which showed a higher ratio [5], [10], [11], [12], [19], [20], [21], [22]. This might come due to the equal amount of male and female traveling in Bali.

Table 3: Types of fractures distribution according to facial regions in our study

\begin{tabular}{|c|c|c|}
\hline Type of fracture & No. of cases & $\%$ \\
\hline \multicolumn{3}{|l|}{ Craniofacial region } \\
\hline Orbital fractures & 46 & \\
\hline \multicolumn{3}{|l|}{ Configuration } \\
\hline Isolated wall & 26 & 56.5 \\
\hline Multiple walls & 20 & 43.5 \\
\hline \multicolumn{3}{|l|}{ Wall } \\
\hline Floor (blowout fracture) & 27 & 58.7 \\
\hline Superior (roof) & 9 & 19.6 \\
\hline Lateral & 15 & 32.6 \\
\hline Inferior orbital rim & 3 & 6.5 \\
\hline Medial & 3 & 6.5 \\
\hline Inferomedial (lamina papyracea) & 9 & 19.6 \\
\hline Frontal sinus wall fractures & 4 & \\
\hline Anterior wall & 4 & 100 \\
\hline Posterior wall & 0 & 0 \\
\hline Frontal bone fractures & 2 & \\
\hline \multicolumn{3}{|l|}{ Maxillofacial/midface region } \\
\hline Maxillary fracture & 28 & \\
\hline - Le fort I & 1 & 3.6 \\
\hline \multicolumn{3}{|l|}{ Sinus wall } \\
\hline Anterior & 18 & 64.3 \\
\hline Posterolateral & 18 & 64.3 \\
\hline Medial & 9 & 32.1 \\
\hline Superior & 8 & 28.6 \\
\hline Inferior & 1 & 3.6 \\
\hline Alveolar process & 4 & 14.3 \\
\hline Fracture of Zygoma & 30 & \\
\hline Four-legged type & 11 & 36.7 \\
\hline Tripod type fractures & 4 & 13.3 \\
\hline Zygomaticomaxillary complex (ZMC) & 6 & 20 \\
\hline Isolated zygomatic arch fractures & 8 & 26.7 \\
\hline Unclassified fracture & 1 & 3.3 \\
\hline \multicolumn{3}{|l|}{ Nasal region } \\
\hline Displaced nasal fracture without septal deviation & 29 & 44.6 \\
\hline Displaced nasal fracture with septal deviation & 25 & 38.5 \\
\hline Non displaced nasal fr. without septal deviation & 4 & 6.6 \\
\hline Non displaced nasal fr. with septal deviation & 7 & 10.8 \\
\hline \multicolumn{3}{|l|}{ Mandibulofacial region } \\
\hline \multicolumn{3}{|l|}{ Number of fracture } \\
\hline Isolated & 8 & 40 \\
\hline Multiple & 12 & 60 \\
\hline \multicolumn{3}{|l|}{ Site } \\
\hline Symphysis & 5 & 25 \\
\hline Parasymphysis & 4 & 20 \\
\hline Body & 3 & 15 \\
\hline Angle (all with associated wisdom tooth) & 3 & 15 \\
\hline Ramus & 13 & 65 \\
\hline Condylar & 3 & 15 \\
\hline Subcondylar & 3 & 15 \\
\hline Coronoid process & 2 & 10 \\
\hline \multicolumn{3}{|l|}{ Configuration } \\
\hline Segmental & 9 & 45 \\
\hline Fragmented & 5 & 25 \\
\hline Splitted & 2 & 10 \\
\hline Simple non-displaced & 4 & 20 \\
\hline Presence of TMJ dislocations & 4 & 20 \\
\hline
\end{tabular}

Those proportions were generally found in the age range of $16-30$, similar to those recorded in other studies [3], [4], [5], [6], [7], [10], [11], [14], [16]. Trauma is much related to young adults because of their 
aggressive nature and they tend to be more carelessly driving on roads [10]. However, by the advance of the age, the number of the incidence of facial fractures in our study tends to decrease, in contrast to a similar study which revealed an increasing number [23]. The low incidence was also found at an earlier age ( $<15$ years old in our study, 3.1\%). A retrospective study performed by Ferreira et al. [19], also found a lesser number of facial fractures involving the children below 16 years of age. It might be explained that children mostly live in a protected environment. Besides, their unique anatomical proportion of cranial-to-facial ratio, lack of sinus pneumatization, frontal projection of cranium, as well as the downward projection of the face lead to a lesser chance of sustaining facial fracture as compared in adult [15], [19], [20]. In our study, such a low incidence of facial fracture at an early age is associated with protection by their family while traveling as well as fewer children travel using motorcycles which leads them to a lesser accident. On the other part, a low incidence of facial fractures in our study is also found in the elderly because most of them spend their vacation in less extreme activities.

Many authors reported MVAs as a majority of the cause of facial fractures [1], [10], [15], [22], consistent with our study. It might be related to large numbers of motorcycles, poorly maintained vehicles, or low driving standards [10]. Inversely, the development of the safety standard of a motor vehicle impacts the decreasing incidence of facial fractures, as reported on a study by McMullin et al. [22] Batista et al. [15] performed the statistical analysis and found that the determinant for the majority of the facial fractures was motorcycle accidents. The finding in our study is quite reasonable since most of the foreigners traveling in Bali are dominated by a young adult who usually travels with rent motorcycles. The number of renting agent is readily available in Bali with cheaper cost of the rent. Besides, there are an increasing number of traffic volumes in the last couple of years. However, two-wheelers in comparison with the cars are more unstable and provide lesser protection [10], thus contributed to the high incidence of the MVA. Fall and assault rank the second and third place in our study, similar to those found in other research [5]. MVAs and assault are known to be related to alcohol consumption [2], [5], [24]. However, their relationship cannot be defined in our study since the early post-trauma detection of blood alcohol level is not a routine assessment performed in our center.

Facial fractures might come with a high incidence of head injuries and soft-tissue injuries involving maxillofacial region, recorded $62.7 \%$ and $56.3 \%$, respectively, in our study. Sigaroudi et al. [17] studied the relationship between midface fractures with brain injuries. It has shown that midface fractures increase the risk of brain injury, thus explains the high incidence of head injury in facial fractures. On the other hand, facial fractures are sometimes associated with non-adjacent injuries (i.e., thoracic, extremities, etc.).
Finding in our study suggested that the majority of facial fractures affected the nasal region (51.6\%), followed by midfacial or maxillofacial region (46\%). It is related due to their prominent anatomic structure and their greater exposure to external trauma [2], [14], very little soft-tissue cover, and relatively unprotected [11]. Most of the nasal fracture presented with low-energy trauma such as violence or assault [12], or even fall. Hence, the existence of assault and fall as the common causes of facial fracture in our study may contribute to the high incidence of a nasal fracture.

The midfacial region acts as a crumple zone when an external force is applied in the cranium and transmitted through the buttress systems [13], [16]. Due to its nature, fracture tends to occur at this point. Furthermore, similar to nasal bone, morphologic prominence of zygoma in defining the facial contour makes it susceptible to traumatic expose. Fractures of zygoma with its configuration encompasses the most common fracture in the midfacial region $(n=30,51.7 \%)$ encountered in our study. In a multivariate logistic regression analysis performed by Batista et al., it was shown that individuals who had suffered a motorcycle accident had an 11-fold increase in the risk of also suffering a maxillary fracture [23].

The incidence of mandible fracture in our study was significantly lower $(n=20,15.9 \%)$ compared to those found in other facial regions. It might be related to lower incidence of assault, where its direct forces are most commonly pointed toward the mandible area. In addition to its mobility, the mandible is lesser traumatized by the injuries caused by MVA and falls, two most common causes of facial fractures in our study, since both of them prone to direct the force to the upper and middle third of facial regions. Furthermore, victims of MVA and fall tend to flex their neck at the time of injury rather than extending it as the protective reflexes. Hence, it might explain the lower incidence of mandible fracture in our study. However, in some studies with comparable demographic characteristics [5], [10], [23], where motor vehicle crashes cause the facial fractures the most, mandible fractures are the majority of the facial fractures encountered. Furthermore, motorcycle accidents were found to be the main risk factor for mandibular fracture [20], [23].

No similar study found the fracture on the craniofacial region (i.e., orbit, frontal sinus) as their most common site. It is in agreement with our study despite the comparable number to those affecting the midfacial and nasal region, i.e., $n=50$ versus $n=65$ and $n=$ 58 , respectively. However, a study conducted by Gari et al. [25], placed facial injuries involving the upper face as their most common injury, contributed by the fact that the upper face was the most exposed area at the time of injury as well as what patients described as a "head first" trajectory at the time of powered watercraft collision. This is quite reasonable to explain how the mechanism of injury might be similar to those applied in the motorbike accident described in our study. 
The frontal bone is the strongest facial bone which requires high force to fracture [18]. In general, the pattern of facial fractures encountered in our study was associated with low-energy fractures. The presence of high-energy fractures (i.e., frontal, Le Fort I, II, III) was significantly lesser in amount. Furthermore, orbital fractures occur along with the other fracture patterns and tend to be the result of high-force injury [16]. Hence, their incidence is lower in comparison to those affecting the nasal and midfacial regions.

Hence, it is concluded that despite similar demographic characteristics, patterns of facial fractures might show a remarkable difference since environmental, social, and cultural factors also play an important role [7]. The conditions where most foreigners in Bali use motorcycles as their chosen transportation lead to a high incidence of MVAs. Thus, regulation for restricting their use might be pointed to as the prevention.

\section{Conclusion}

As conclusion, despite similar demographic characteristics, patterns of facial fractures might show a remarkable difference since environmental, social, and cultural factors also play an important role. The conditions where most foreigners in Bali use motorcycles as their chosen transportation lead to a high incidence of MVAs. Thus, regulation for restricting their use might be pointed to as the prevention.

\section{References}

1. Malara P, Malara B, Drugacz J. Characteristics of maxillofacial injuries resulting from road traffic accidents--a 5 year review of the case records from department of maxillofacial surgery in Katowice, Poland. Head Face Med. 2006;2:27. https://doi. org/10.1186/1746-160x-2-27

\section{PMid:16938135}

2. Leles JL, Santos EJ, Jorge FD, Da Silva ET, Leles CR. Risk factors for maxillofacial injuries in a Brazilian emergency hospital sample. J Appl Oral Sci. 2010;18(1):23-9. https://doi. org/10.1590/s1678-77572010000100006 PMid:20379678

3. Maliska MC, Lima SM Jr., Gil JN. Analysis of 185 maxillofacial fracture in the state of Santa Catarina Brazil. Braz Oral Res. 2009;23(3):268-74. https://doi.org/10.1590/ s1806-83242009000300008

4. Khitab U, Ansari SR, Khan A, Khan MT, Salam A. Occurrence and characteristics of maxillofacial injuries-a study. Pak Oral Dent J. 2010;30(1):57-61.

5. Al Ahmed HE, Jaber MA, Abu Fanas SH, Karas M. The pattern of maxillofacial fractures in Sharjah, United Arab Emirates: A review of 230 cases. Oral Surg Oral Med Oral Pathol Oral Radiol Endod. 2004;98(2):166-70. https://doi.org/10.1016/j. tripleo.2004.01.020

PMid:15316543

6. Momeni H, Shahnaseri S, Hamzeheil Z. Distribution assessment of maxillofacial fractures in trauma admitted patients in Yazd Hospitals: An epidemiology study. Dent Res J. 2011;8(5):S80-3. PMid:23372601

7. Abbas I, Fayyaz M, Shah I, Khan MA, Qazi SH, Munir N, et al. Demographic distribution of maxillofacial fractures in Ayub Teaching Hospital: 7-year review. J Ayub Med Coll Abbottabad. 2009;21(2):110-2.

PMid:20524484

8. Reuben AD, Watt-Smith SR, Dobson D, Golding SJ. A Comparative study of evaluation of radiographs, CT and $3 D$ reformatted CT in facial trauma: What is the role of $3 \mathrm{D}$ ? $\mathrm{Br}$ J Radiol. 2005;78(927):198-201. https://doi.org/10.1259/ bjr/26977910

PMid: 15730983

9. Exadaktylos AK, Eggensperger N, Eggli S, Smolka K, Zimmermann H, lizuka T. Sports related maxillofacial injuries: The first maxillofacial trauma database in Switzerland. $\mathrm{Br}$ J Sports Med. 2004;38(6):750-3. https://doi.org/10.1136/ bjsm.2003.008581

PMid: 15562172

10. Chandra Shekar BR, Reddy CV. A five-year retrospective statistical analysis of maxillofacial injuries in patients admitted and treated at two hospitals of Mysore City. Indian J Dent Res. 2008;19(4):304-8. https://doi.org/10.4103/0970-9290.44532 PMid:19075432

11. Hwang K, You SH. Analysis of facial bone fractures: An 11-year study of 2,094 patients. Indian J Plast Surg. 2010;43(1):42-8. https://doi.org/10.4103/0970-0358.63959 PMid:20924449

12. Salonen EM, Koivikko MP, Koskinen SK. Violence-related facial trauma: Analysis of multidetector computed tomography findings of 727 patients. Dentomaxillofac Radiol 2010;39(2):107-12. https://doi.org/10.1259/dmfr/67015359 PMid:20100923

13. Bryan M, Driscoll B. Midface Fractures. Available from: http:// www.otohns.net. [Last accessed on 2012 Nov 02].

14. Adeyemo WL, Ladeinde AL, Ogunlewe MO, James O. Trends and characteristics of oral and maxillofacial injuries in Nigeria: A review of the literature. Head Face Med. 2005;1:7. https://doi. org/10.1186/1746-160x-1-7 PMid:16270942

15. Batista AM, Ferreira Fde O, Marques LS, Ramos-Jorge ML, Ferreira MC. Risk factors associated with facial fractures. Braz Oral Res. 2012;26(2):119-25. https://doi.org/10.1590/ s1806-83242012000200006

PMid:22473346

16. Punjabi SK, Rehman HU, Ali Z, Ahmed S. Causes and management of zygomatic bone fractures at Abbasi Shaheed Hospital Karachi (Analysis of 82 patients). J Pak Med Assoc. 2011;61(1):36-9. PMid:22368900

17. Sigaroudi AK, Saberi BV, Chabok SY. The relationship between mid-face fractures and brain injuries. J Dent Shiraz Univ Med Sci. 2012;13(1):18-22.

18. Fraioli RE, Branstetter BF, Deleyiannis FW. Facial fractures: Beyond le fort. Otolaryngol Clin North Am. 2008;41(1):51-76. https://doi.org/10.1016/j.otc.2007.10.003

19. Ferreira PC, Amarante JM, Silva PN, Rodrigues JM, Choupina MP, Silva AC, et al. Retrospective study of 1251 maxillofacial fractures in children and adolescents. Plast Reconstr Surg. 2005;115(6):1500-8. https://doi.org/10.1097/01. 
prs.0000160268.20294.fd

PMid:15861052

20. Alcalá-Galiano A, Arribas-García IJ, Martín-Pérez MA, Romance A, Montalvo-Moreno JJ, Juncos JM. Pediatric facial fractures: Children are not just small adults. Radiographics. 2008;28(2):441-61. https://doi.org/10.1148/rg.282075060 PMid: 18349450

21. Garr JI, Perlyn CA, Johnson MJ, Mobley SR, Shatz DV, Kirton OC, et al. Patterns of maxillofacial injuries in powered watercraft collision. Plast Reconstr Surg. 1999;104(4):922-7. https://doi.org/10.1097/00006534-199909040-00005

22. Aydin OE, Tan O, Algan S, Kuduban SD, Barin ZE, Cinal A, et al. Maxillofacial fracture experiences: A review of 152 cases. Eurasian J Med. 2012;44(3):141-3. https://doi.org/10.5152/ eajm.2012.33
PMid:25610228

23. Kim SH, Lee SH, Cho PD. Analysis of 809 facial bone fractures in a pediatric and adolescent population. Arch Plast Surg. 2012;39(6):606-11. https://doi.org/10.5999/aps.2012.39.6.606

PMid:23233885

24. McMullin BT, Rhee JS, Pintar FA, Szabo A, Yoganandan M. Facial fractures in motor vehicle collisions: Epidemiological trends and risk factors. Arch Facial Plast Surg. 2009;11(3):16570. https://doi.org/10.1001/archfacial.2009.11

PMid: 19451450

25. Back CP, McLean NR, Anderson PJ, David DJ. The conservative management of facial fractures: Indications and outcomes. J Plast Reconstr Aesthet Surg. 2007;60(2):146-51.

PMid:17223512 